\title{
Correction to: Examining Caretaker Attitudes Towards Primary Prevention of Pediatric Behavioral Health Problems in Integrated Care
}

Martha Zimmermann, MA

William O'Donohue, $\mathrm{PhD}$

Monica Zepeda, BA Alexia Woodley, BS

\author{
Correction to: J Behav Health Serv Res. \\ https://doi.org/10.1007/s11414-020-09720-6
}

The correlation between child age and caretaker age reported in Table 2 was incorrectly reported as .051 . Table 2 has been revised to indicate that the correlation between child age and caretaker age was 0.51 . In addition, the revised article has corrected errors in the formatting of the confidence intervals. The original article has been corrected.

Publisher's Note Springer Nature remains neutral with regard to jurisdictional claims in published maps and institutional affiliations.

The online version of the original article can be found at https://doi.org/10.1007/s11414-020-09720-6

Address correspondence to Martha Zimmermann, MA, Department of Psychology, University of Nevada, 1664 N.Virginia St, Reno, NV 89557, USA.

William O’Donohue, PhD, Department of Psychology, University of Nevada, Reno, NV, USA.

Monica Zepeda, BA, Department of Psychology, University of Nevada, Reno, NV, USA.

Alexia Woodley, BS, Department of Psychology, University of Nevada, Reno, NV, USA. 